Article

\title{
Formation of Large Size Precipitate-Free Zones in $\beta$ Annealing of the Near- $\beta$ Ti-55531 Titanium Alloy
}

\author{
Xueqi Jiang ${ }^{1,2}$, Xiaoqiang Shi ${ }^{3}$, Xiaoguang Fan ${ }^{1,2, *}$ and Qi Li ${ }^{1,2}$ \\ 1 State Key Laboratory of Solidification Processing, School of Materials Science and Engineering, \\ Northwestern Polytechnical University, Xi'an 710072, China; jiangxueqi@mail.nwpu.edu.cn (X.J.); \\ rickey@mail.nwpu.edu.cn (Q.L.) \\ 2 Shaanxi Key Laboratory of High-Performance Precision Forming Technology and Equipment, Northwestern \\ Polytechnical University, Xi'an 710072, China \\ 3 Lanzou Istitute of Physics, Chinese Academy of Space Technology, Lanzhou 730000, China; sxq510@126.com \\ * Correspondence: fxg3200@nwpu.edu.cn; Tel.: +86-29-88460212-809; Fax: +86-29-88495632
}

Received: 18 April 2019; Accepted: 6 May 2019; Published: 10 May 2019

\begin{abstract}
Large size $\left(>10000 \mu \mathrm{m}^{2}\right)$ precipitate-free zones in the absence of microsegregation were observed in the near- $\beta$ Ti-55531 titanium alloy after furnace cooling from high temperature and longtime annealing in the single- $\beta$ phase field. To reveal the formation mechanism of the large size precipitate-free zone, continuous cooling and isothermal heat treatment were carried out to investigate the $\beta-\alpha$ phase transformation process. It was found that the large size precipitate free zone is attributed to the heterogeneous nucleation of $\alpha$ phase. The nucleation site evolves in three different modes: I-random nucleation inside the $\beta$ grain, II-network nucleation inside the $\beta$ grain and, III-heterogeneous nucleation on the precipitated $\alpha$ phase. Modes I and II lead to homogeneous transformed structure while Mode III results in the large size precipitate-free zone. Both modes II and III are promoted at high annealing temperature, rapid cooling above $600{ }^{\circ} \mathrm{C}$ or slow cooling below $600^{\circ} \mathrm{C}$. Mode II is common as it can minimize the strain energy in phase transformation. As a result, the formation of the large size precipitate-free zone is not deterministic.
\end{abstract}

Keywords: precipitate-free zone; phase transformation; heterogeneous nucleation; network structure; titanium alloys

\section{Introduction}

Titanium alloys have attracted more and more attention because of the combination of superior mechanical and physical properties, such as high strength, low density, good thermal stability and excellent corrosion resistance [1]. Ti-55531(Ti-5Al-5Mo-5V-3Cr-1Zr) is a relatively new near $\beta$ titanium alloy, based on the Russian alloy VT22, with high strength and high toughness. It can be used to manufacture the large size load-bearing components such as airframe and aircraft landing gear because of its great hardenability, hot deformability and ability that can match different indexes of strength and toughness $[2,3]$.

The mechanical properties of the Ti-55531 alloy component are strongly influenced by its microstructure [4]. Thus, heat treatment is often employed to modulate the microstructure along with thermo-mechanical processing. For Ti-55531 alloy, $\beta$ annealing is often used to homogenize the material and obtain a transformed structure which consists of lamellar $\alpha$ and residual $\beta$ phase. The microstructure is sensitive to heat treatment process parameters, cooling rates, cooling mode and holding time in heat treatment. Microstructural defects may take place if inappropriate parameters are adopted. This paper found that the microstructure after $\beta$ annealing can be extraordinary heterogeneous and there were large size precipitate-free zones (PFZs) in some of the specimens, as shown in Figure 1. 
These large size PFZs act as soft zones, where preferential deformation occurs prior to the onset of dislocation motion in the harder matrix [5], and affect the mechanical properties and hot working properties of the Ti-55531 alloy. The PFZs near grain boundaries result in intergranular fracture and waken the ductility [6]. Narita [7] found that the existence of PFZs in $\beta$ type titanium alloy decreases ductility and tensile strength. Decreases in width of the PFZ improved the tensile properties, and the presence of the PFZ was found to be harmful to the fracture [8].

Typically, when the $\beta$ titanium alloy is solution treated above the $\beta$ transus $\left(T_{\beta}\right)$ and quenched, the athermal $\alpha$ precipitates may undergo coarsening and act as uniformly distributed heterogeneous nucleation sites for $\alpha$ precipitates form on the subsequent isothermal aging. Such nucleation mode often prohibits the formation of PFZs. In fact, small size PFZs are often observed near the original $\beta$ grain boundaries in aged $\beta$ titanium alloy. Liu et al. [6] showed that the grain boundary $\alpha$ phase $\left(\alpha_{\mathrm{GB}}\right)$ normally exhibited continuous layer morphology because $\alpha$ phase nucleates and grows preferentially at $\beta$ grain boundaries during $\beta-\alpha$ phase transformation. Accompanied by the formation of $\alpha_{\mathrm{GB}}, \alpha$ stabilizers ( $\mathrm{Al}$ and $\mathrm{O}$ ) diffuse into the $\alpha_{\mathrm{GB}}$ from the adjacent zone in which the $\beta$ phase is subsequently stabilized. This prevents the precipitation of the fine hardening $\alpha_{\mathrm{s}}$, and results in the formation of soft PFZs along the $\alpha_{\mathrm{GB}}$. Lütjering et al. [5] suggested that the $\beta$ matrix is occupied by fine semi-coherent precipitates and incoherent particles of the equilibrium phase are precipitated in the grain boundaries, resulting in depletion of solute atoms in the grain boundary area. This causes the formation of PFZs along the grain boundaries. Similarly, Narita et al. [7] suggested that the segregation of interstitial elements creates precipitate-free zones. It is notable that the PFZs mentioned above are all along the grain boundaries and arise from the microsegregation of alloying elements. However, the PFZs in the current investigation are much larger and they often locate within the $\beta$ grains. Thus the formation of large size PFZs in Ti-55531 alloy may not be interpreted in terms of the diffusing of $\alpha$ stabilizers.
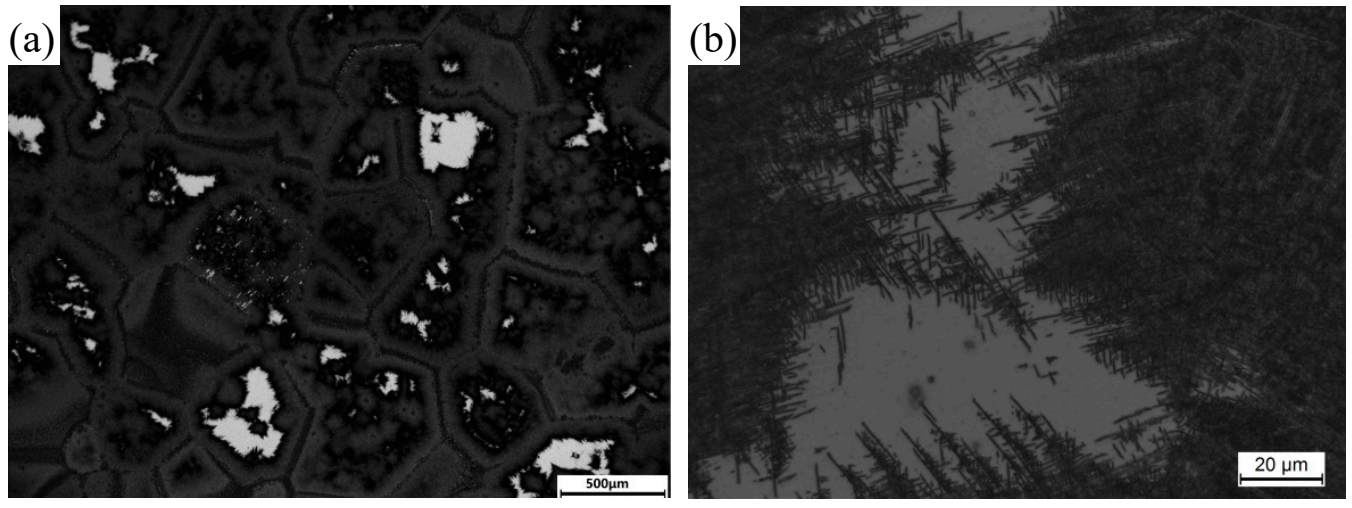

Figure 1. The large size PFZs after $\beta$ annealing (a); a close inspection of PFZ (b).

The microstructure of the heat-treated metallic material is determined by the nucleation and growth process in phase transition. The $\beta / \alpha$ phase transformation kinetics of the $\beta$-metastable titanium alloy Ti17 was studied by Teixeira et al. [9]. They reported two main precipitation mechanisms of the $\alpha$ phase during the cooling from the $\beta$ phase field. At high temperatures, the following sequence is

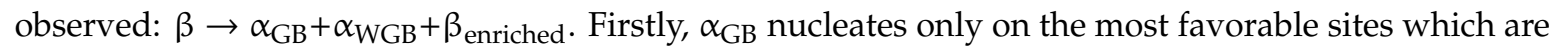
the grain boundaries and grows by diffusion. Then, colonies constituted of parallel lamellae of $\alpha_{\text {WGB }}$ (Widmanstätten morphology) nucleate on $\alpha_{\mathrm{GB}}$. The growth of $\alpha_{\mathrm{WGB}}$ is diffusion controlled. At lower temperatures, $\beta \rightarrow \alpha_{\mathrm{WI}}+\beta_{\text {enriched }}$ occurs on intragranular nucleation sites. A more displacive character could be associated with the transformation. The nucleation can occur on less favorable sites as the dislocations, because of the higher driving force. However, to understand the formation mechanism of large size PFZs, it is necessary to understand the specific nucleation and growth behaviors in the phase transformation process.

The aim of the present work is to investigate the characteristics and formation mechanism of large size PFZs in $\beta$ annealing of Ti-55531 titanium alloy. To this end, different heat treatment processes 
including continuous cooling and isothermal cooling combined with metallographic analysis were set on the Ti-55531 titanium alloy. The formation of large size PFZs is interpreted in terms of the nucleation and growth of the $\alpha$ phase. The results can guide the defect control in hot working of the near- $\beta$ titanium alloys.

\section{Material and Procedures}

\subsection{Material}

The chemical composition of the as-received Ti-55531 alloy was 5.39Al, 4.80Mo, 4.95V, 2.90Cr, $1.09 \mathrm{Zr}, 0.32 \mathrm{Fe}, 0.014 \mathrm{C}, 0.007 \mathrm{~N}, 0.11 \mathrm{O}$ and balanced $\mathrm{Ti}$ (in wt \%). The $\beta$ transus temperature $\left(\mathrm{T}_{\beta}\right)$ was about $845^{\circ} \mathrm{C}$ measured by the metallographic method. The as-received material was a hot forged bar whose microstructure consists of primary equiaxed $\alpha$ phase within transformed $\beta$ matrix, as shown in Figure 2a.

The specimens with the specification of $100 \times 100 \times 100 \mathrm{~mm}$ machined from the as-received material were heated to $950{ }^{\circ} \mathrm{C}$ in the resistance furnace SXL1200 (manufactured in Shanghai, China), held for $120 \mathrm{~min}$ and then cooled in furnace (FC) to coarsen the prior $\beta$ grains. The average $\beta$ grain size is about $500 \mu \mathrm{m}$, as shown in Figure $2 \mathrm{~b}$. The specimens after prior heat treatment were cut to cylinder samples of $\varphi 10 \mathrm{~mm} \times 15 \mathrm{~mm}$ by wire-electrode cutting for subsequent heat treatment.
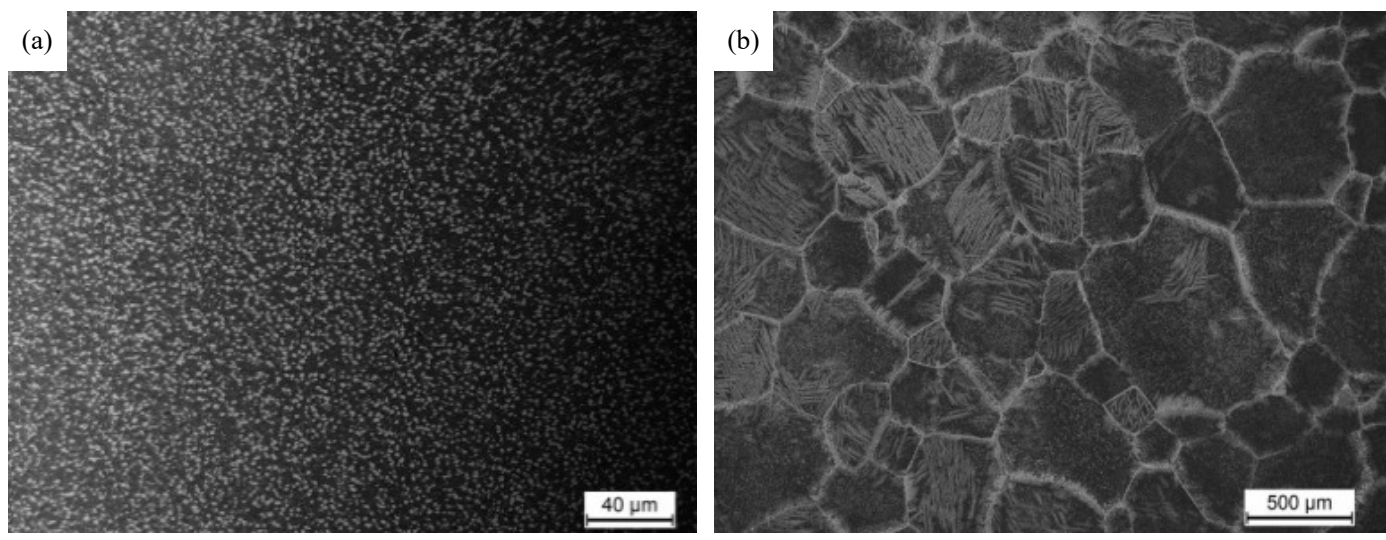

Figure 2. The initial microstructure of the Ti-55531 titanium alloy: (a) as-received microstructure, (b) after prior $\beta$ heat treatment.

\subsection{Experimental Procedures}

The heat treatment was conducted in the resistance furnace AZBIL-SDC24 equipped with ventilation device. The furnace could provide precisely control on the cooling rate by programing. There are three kinds of heat treatment applied in this work. (i) Furnace cooling without specific control of cooling rate (Figure 3a). The samples were heated to peak temperatures of $865{ }^{\circ} \mathrm{C}$ held for $30 \mathrm{~min}$ (or $950{ }^{\circ} \mathrm{C} / 10 \mathrm{~min}$ ), and then cooled in furnace (FC) and water quenched after reaching prescribed temperatures for freezing the microstructure to room temperature. The vari (ii) precise control was operated during continuous cooling process (Figure $3 \mathrm{~b}$ ). The samples were heated to the annealing temperature, held for $30 \mathrm{~min}$, then cooled with the cooling rate of $0.5,1,2$ and $5{ }^{\circ} \mathrm{C} / \mathrm{min}$ and water quenched after reaching prescribed temperatures of 710, 690, 680, 670, 660 and $600{ }^{\circ} \mathrm{C}$ for preserving the microstructure to room temperature. (iii) Isothermal heat treatment (Figure 3c). The samples were heated to $865^{\circ} \mathrm{C}$ ( or $950{ }^{\circ} \mathrm{C}$ ), held for $30 \mathrm{~min}$, transferred to another furnace at lower temperature $\left(700,660,620,600,580^{\circ} \mathrm{C}\right)$ immediately, isothermal held for 10, 30, 60, $120 \mathrm{~min}$ and then air cooled The specimens for metallographic examination were mechanically polished and etched with a solution consisting of 1 part $\mathrm{HF}, 3$ parts $\mathrm{HNO} 3$ and 7 parts $\mathrm{H}_{2} \mathrm{O}$. The microstructures were observed by optical microscopy (OM) and scanning electron microscopy (SEM). Microstructure evolution behavior was then quantified using moderate magnification photographs by a quantitative metallographic 
image analysis system (Image Pro plus 6.0). It is notable that the phase fraction, length and width of $\alpha$ phases were repetitively measured in different areas and/or samples, thus the values of average phase fraction, average length and average width of distinct $\alpha$ phases thereinafter are of statistical significance. The average compositions of the surface and spots were determined by Energy Disperse Spectroscopy (EDS).

(a)

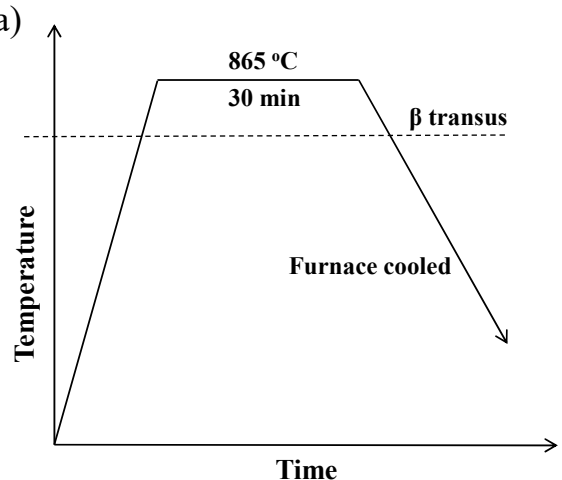

(b)

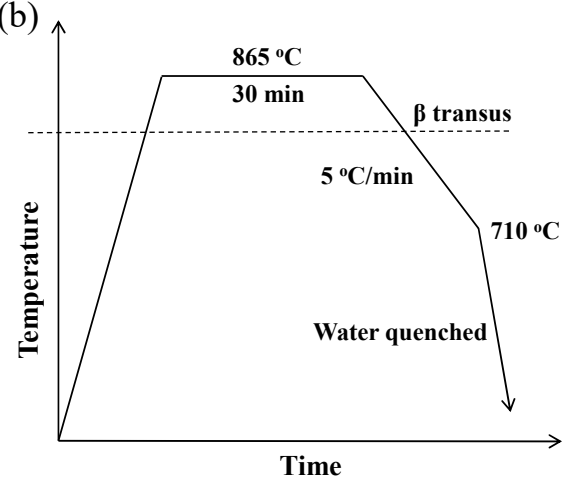

(c)

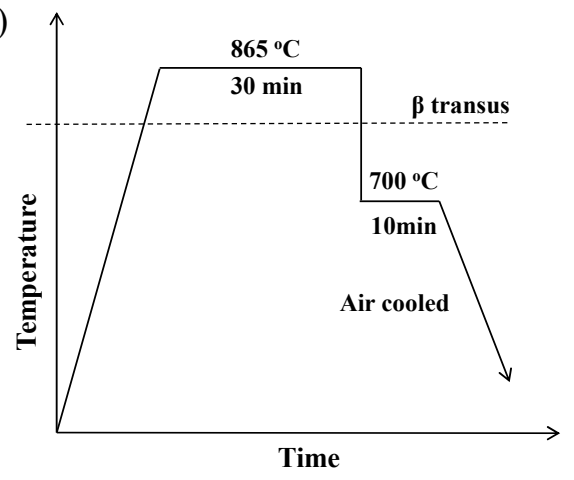

Figure 3. The schematic diagram of heat treatment scheme of: (a) furnace cooling without specific control; (b) continuous cooling process; (c) isothermal heat treatment.

\section{Results}

\subsection{Characteristics of the Large Size PFZs}

Typical micrographs of the large size PFZs is shown in Figure 1. The specimen was heated to $950{ }^{\circ} \mathrm{C}$, held for $2 \mathrm{~h}$ and cooled in the furnace to $650^{\circ} \mathrm{C}$, held for $2 \mathrm{~h}$ and then cooled in the furnace to room temperature (RT). The volume fraction of the PFZs is about $10 \%$. Most PFZs are inside the grains and their shapes are irregular. There can be several PFZs in one grain. Meanwhile, there are some grains free of PFZs. The size of PFZs is about hundreds of microns. There are also some small PFZs which are less than $15 \mu \mathrm{m}$. There is no relationship between the size of PFZs and the shape and size of the grain. As microstructure observation is carried out on a specific section, the actual shape of PFZs may not be deduced by the section.

The PFZs are surrounded by fine $\alpha$ lamellae. These $\alpha$ precipitations are fine and uniform outside the PFZs. The morphology of the $\alpha$ lamellae is somewhat similar to the so-called basket-weave structure. Some long parallel $\alpha$ lamellae with limited interval are formed preferentially. Then, new $\alpha$ lamellae nucleate on the broad face of the existing $\alpha$ lamellar and grow perpendicular to that such that the interval is occupied by short lamellae. On the rim of the PFZs, there are some lamellae growing to the interior of the PFZs. Some clustered $\alpha$ phase may also exist inside the PFZs. The morphology of the $\alpha$ laths near the PFZs are the same to that elsewhere. 
The mechanical properties of the PFZs were also tested by micro hardness. Three trial points were selected from PFZs, in which the average Vickers hardness was 272.33 MPa. On the other hand, the average Vickers hardness is 395MPa in transformed $\beta$ matrix. Since PFZs are of more softness, the yield stress between PFZs and the adjacent zones is of much more difference so that cracks are likely to nucleate early at the boundaries.

There are two possibilities about the occurrence of the large size PFZs. Many researchers [5,6] [10] found that the segregation of $\beta$ stabilizers, like Mo and Fe, leads to $\beta$ flecks. However, the EDS test results shown in Figure 4 indicate that there is no obvious segregation on the main alloying elements (Table 1). So there is a possibility that the PFZs appear during the transformation process. The nonuniform precipitation results in the occurrence of PFZs. It is essential to study the transformation course of Ti-55531 alloy on the continuous cooling condition.

It is noteworthy that the formation of large size PFZs are not always observed even under the same heat treatment condition. The same heat treatment was applied on 128 specimens and 62 of them had large size PFZs.

Table 1. Average weight of elements of Ti-55531 alloy in PZ and PFZ.

\begin{tabular}{ccccccccc}
\hline \multirow{2}{*}{ Element } & \multicolumn{2}{c}{ Al } & \multicolumn{2}{c}{ V } & \multicolumn{2}{c}{ Cr } & \multicolumn{2}{c}{ Mo } \\
& PZ & PFZ & PZ & PFZ & PZ & PFZ & PZ & PFZ \\
\hline wt. $\%$ & 5.34 & 5.38 & 4.96 & 4.91 & 2.85 & 2.74 & 5.90 & 5.77 \\
\hline
\end{tabular}
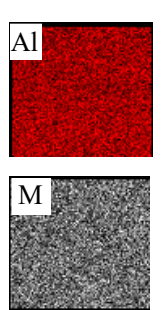
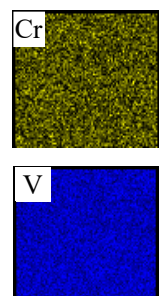
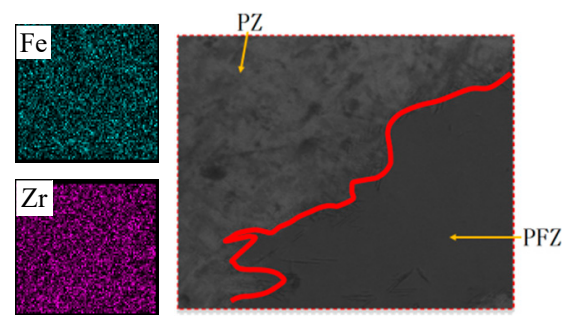

Figure 4. The distribution of elements of selected area and corresponding scanning area in energy disperse spectroscopy (EDS) test.

\section{2. $\beta$ - $\alpha$ Phase Transformation of Ti-55531 Alloy}

Figure 5 illustrates the microstructure evolution during furnace cooling from $950{ }^{\circ} \mathrm{C}$. It is noteworthy that the large size PFZs did not appear in this case. The $\alpha$ phase appeared firstly at the prior $\beta$ grain boundaries as expected. Meanwhile, there were also some $\alpha$ phase nucleated inside the $\beta$ grains. The $\alpha_{\mathrm{GB}}$ precipitated incompletely and only few $\beta$ grain boundaries were decorated at $800{ }^{\circ} \mathrm{C}$. The nucleation sites were rare and distributed randomly inside the grain.

As the temperature decreased to $640{ }^{\circ} \mathrm{C}$ (Figure 5a), the grain boundaries were further coarsened. On a few boundaries, the grain boundary Widmanstatten $\left(\alpha_{W G B}\right)$ was observed, especially at the triple junctions. The $\alpha_{\text {WGBs }}$ were short and thick as they formed at relatively high temperature. There were still few nuclei inside the prior $\beta$ grains. Moreover, new $\alpha$ phase nucleated on the precipitated $\alpha$ phase is scarcely observed.

When the specimen was cooled to $600{ }^{\circ} \mathrm{C}$ (Figure 5b), a lot of thin lamellae $\alpha$ were observed near the prior $\beta$ grain boundaries. The $\alpha$ lamellae were disordered and in basket-weave or feather-like forms. Clusters of thin $\alpha$ lamellae were also observed within the prior $\beta$ grains. The morphology of the intra-grain $\alpha$ lamellae was similar to that on the grain boundaries, indicating typical heterogeneous nucleation in this temperature range.

A huge amount of $\alpha$ phase precipitated both at the boundaries and inside the grains when the temperature dropped to $580{ }^{\circ} \mathrm{C}$, as shown in Figure $5 \mathrm{c}$. It is interesting to see that the precipitated $\alpha$ phase show a hierarchic structure. A network of $\alpha$ phase formed within the prior $\beta$ grains, separating the $\beta$ grains into cells of about $10-50 \mu \mathrm{m}$ in diameter. The cell walls were constructed by interlaced thin $\alpha$ lamellae. 
In most cases, such heterogeneous precipitation of the secondary phase is caused by the substructures within the prior $\beta$ grains. Thus, electron backscattered diffraction (EBSD) microscopy was employed to measure the grain orientation variation within prior $\beta$ grains, as shown in Figure 6 . It is clear that all the cells had the same orientation, i.e., there was no substructure within the prior $\beta$ grains (The scatted points with other colors at the cell walls were the $\alpha$ phase). The formation of network structure will be discussed in Section 4.

On the basis of the network structure, new $\alpha$ phase continuously nucleated at the cell walls and grew into the cells, as shown in Figure $5 \mathrm{~d}$. Most of the $\beta$ matrix was occupied by the $\alpha$ phase. There were still some PFZs scattered in the $\beta$ matrix. However, the size of the PFZs was much smaller than that in Figure 1. It means the formation of network structure can homogenize the microstructure after cooling. If the network structure is unavailable during cooling, the large size PFZs will form.
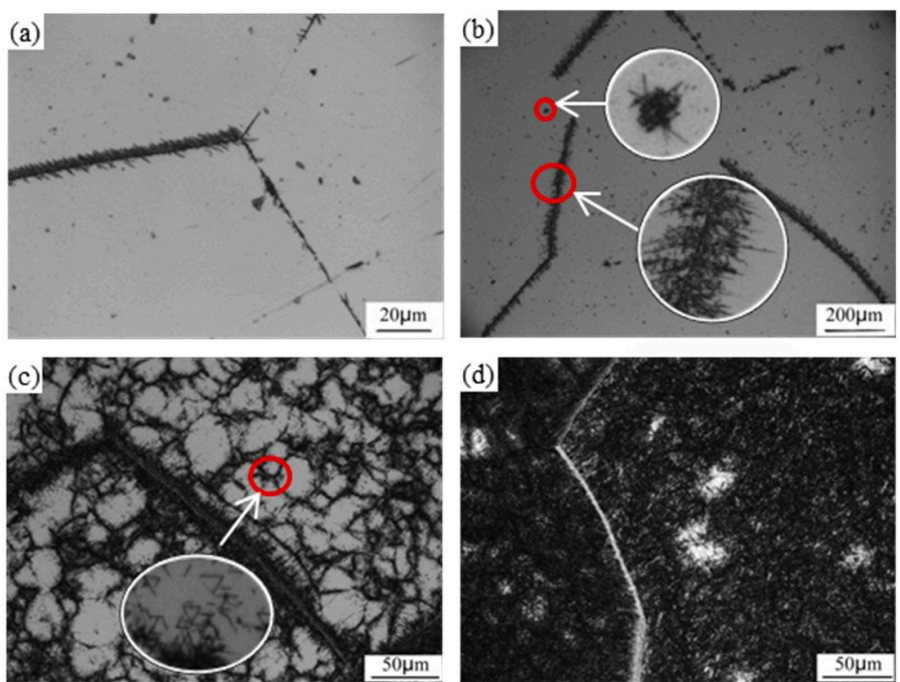

Figure 5. Microstructural developments during furnace cooling from $950{ }^{\circ} \mathrm{C}$ to (a) $640{ }^{\circ} \mathrm{C}$; (b) $600{ }^{\circ} \mathrm{C}$; (c) $580{ }^{\circ} \mathrm{C}$; (d) Room temperature.

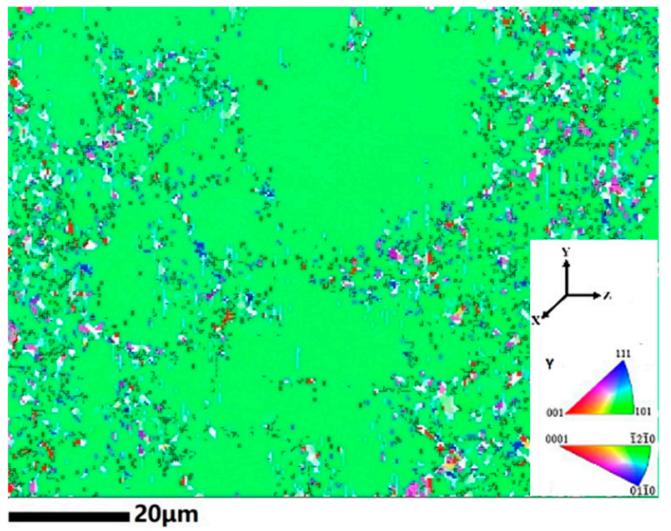

Figure 6. Inverse pole figure (IPF) map of the network structure.

\subsection{Effect of Processing Parameter on Phase Transformation}

\subsubsection{Continuous Cooling}

Figure 7 shows the microstructure after controlled cooling to $660{ }^{\circ} \mathrm{C}$. At the lowest cooling rate of $0.5^{\circ} \mathrm{C} / \mathrm{min}$, most of the $\beta$ phase transformed to the $\alpha$ phase and a typical basket-weave structure was formed. The PFZs distributed homogenously between the $\alpha$ lamellae, as shown in Figure 7a. The length of $\alpha$ lamellae can be as high as $100 \mu \mathrm{m}$ (Figure 7e). However, high magnified micrographs show that the $\alpha$ 
lamellae were composed of a chain of equiaxed $\alpha$ particles, indicating sympathetic nucleation of the $\alpha$ phase was much easier under low cooling rate. Both the length and fraction of the $\alpha$ phase decrease with the cooling rate as expected (Figure 7e,f). Moreover, the distribution and morphology of the $\alpha$ phase were also changed. Taking the neighboring parallel $\alpha$ lamellae as a single colony, it is clear that the width of the colony was much smaller than the length of the lamellae. The sympathetic nucleation was suppressed at the high cooling rate. This means the nucleation of the $\alpha$ phase became independent with the increasing cooling rate. The nucleation sites are more confined to the crystal defects at the high cooling rate. As a result, the $\alpha$ phase was clustered at the high cooling rate, leaving some $\beta$ matrix without $\alpha$ precipitates (Figure $7 \mathrm{~b}-\mathrm{d}$ ).

After prior heat treatment, the $\beta$ grains are completely surrounded by the thin layers of alpha-phase (Figure 1b). But in Figure 7b-d, these layers break into individual flakes, which may be connected with the so-called complete, incomplete and pseudopartial wetting of grain boundaries by the second solid phase [11]. The morphology of grain boundary layers strongly influences the properties of Ti-alloys [12]. The grain boundary wetting transitions may influence the formation of PFZs.
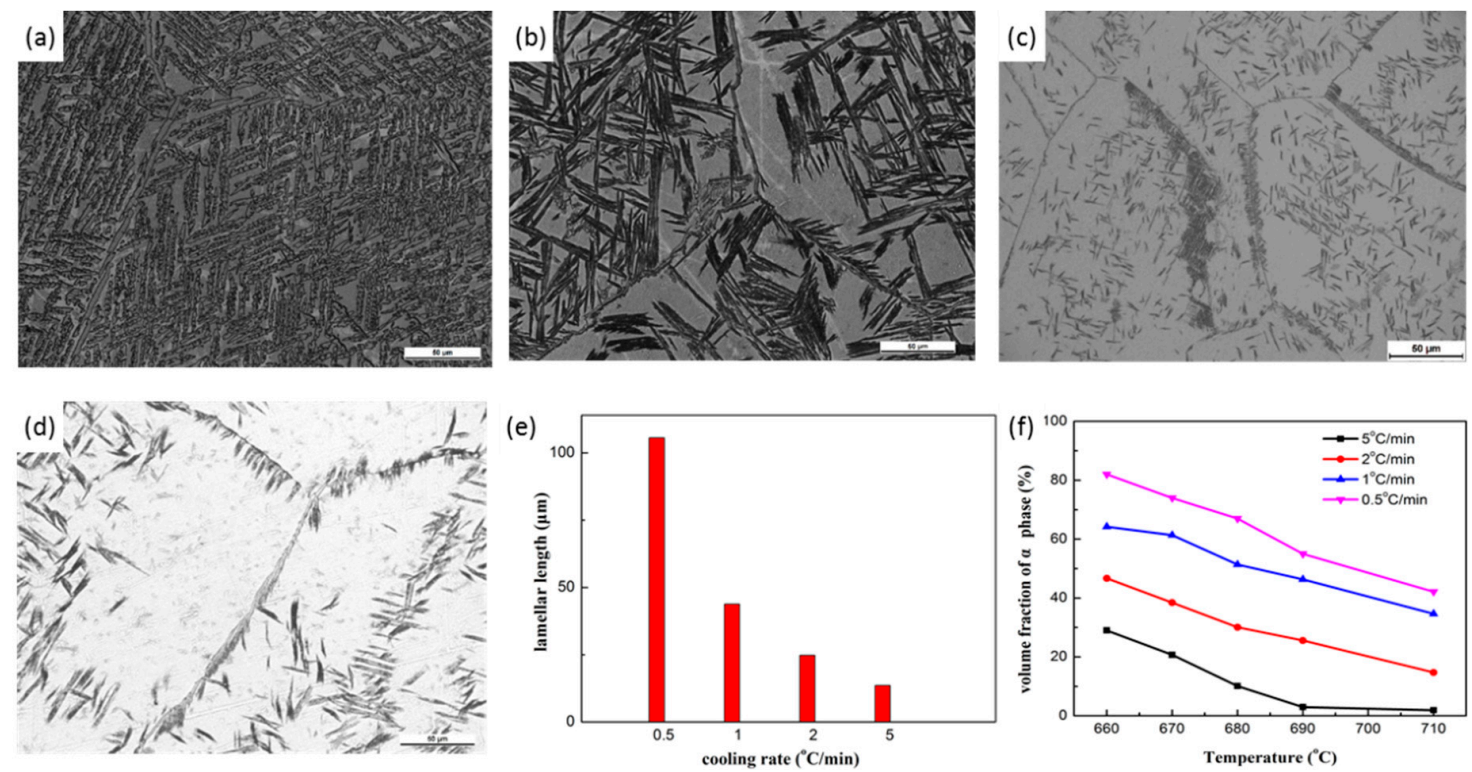

Figure 7. Effect of the cooling rate on the nucleation and growth of the $\alpha$ phase. The specimens were cooled at (a) 0.5, (b) 1, (c) 2 and (d) $5{ }^{\circ} \mathrm{C} / \mathrm{min}$ from $865^{\circ} \mathrm{C}$ to $660^{\circ} \mathrm{C}$. The measured length and volume faction of the $\alpha$ phase are given in (e) and (f).

The solution temperature had great influence on the phase transformation process, as shown in Figure 8a. The holding time is $10 \mathrm{~min}$. The transformation kinetics decreased with increasing solution temperature, as both the nucleation and growth of the $\alpha$ phase were retarded. This is because the high temperature holding eliminated the crystal defects in prior $\beta$ grains and suppressed the heterogeneous nucleation. Moreover, the diffusion process was retarded with decreasing defects. As a result, the diffusion-control growth was also slown down.

When the solution temperature is $860-910^{\circ} \mathrm{C}$, with the increasing solution temperature, the volume fraction of $\alpha$ phase is decreasing and the decreasing rate is high. When the solution temperature is above $910^{\circ} \mathrm{C}$, the volume fraction of $\alpha$ phase is decreasing with the increasing solution temperature and the decreasing rate is low. Thus, PFZs is prone to occurrence when the solution temperature is above $910{ }^{\circ} \mathrm{C}$. The transformation kinetics given in Figure $8 \mathrm{~b}$ suggested that the $\beta$ - $\alpha$ transformation prevailed below $600{ }^{\circ} \mathrm{C}$ and finished at about $550{ }^{\circ} \mathrm{C}$ when the high solution temperature was applied. In fact, the temperature range in which rapid phase transformation occurs can be changed. An example is given in Figure $8 \mathrm{~b}$ that the temperature range was $710-660{ }^{\circ} \mathrm{C}$ at the solution temperature of $865^{\circ} \mathrm{C}$. The PFZs can also be suppressed if phase transformation occurs at high temperature. 

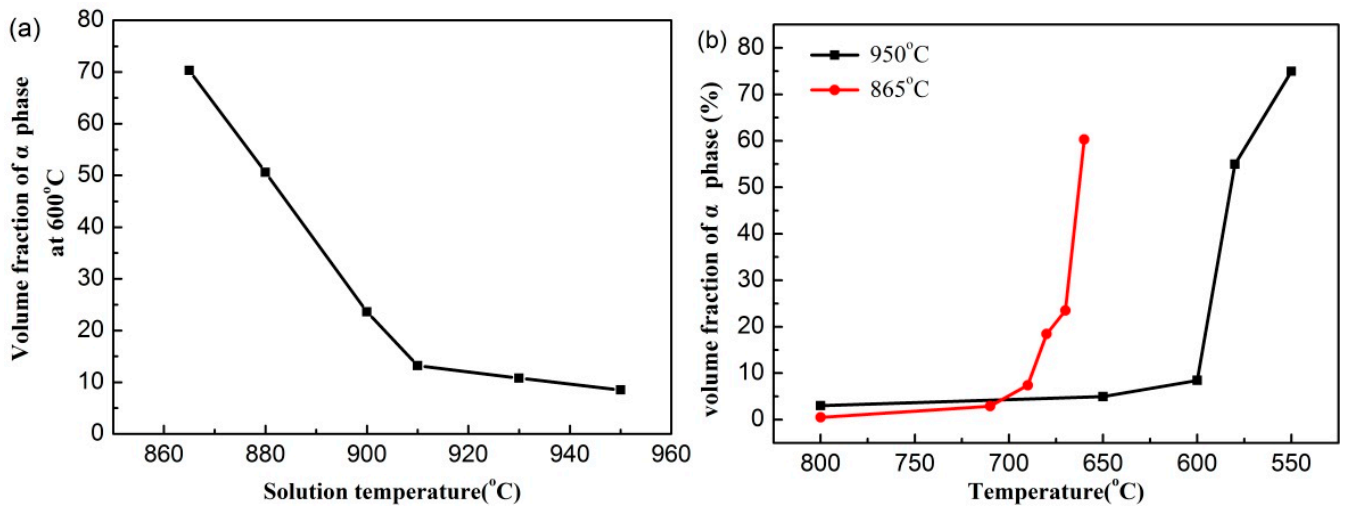

Figure 8. Effect of solution temperature on phase transformation during furnace cooling: (a) volume fraction of $\alpha$ phase at $600{ }^{\circ} \mathrm{C} ;(\mathbf{b})$ phase transformation kinetics at different temperatures.

\subsubsection{Isothermal Treatment}

The microstructure evolution during isothermal heat treatment process is given in Figure 9. At the beginning of the isothermal holding, a few $\alpha_{\mathrm{GB}}$ appeared and some of them showed a connected morphology while the other were separated, as shown in Figure 9a. It seems that the nucleation sites of the $\alpha$ phase were randomly distributed inside grains. The intra-grain $\alpha$ phase were in equiaxed form. This is quite similar to that in the early stage of continuous cooling. With increasing holding temperature, a large fraction of lamellae $\alpha$ appeared at the prior $\beta$ grain boundaries and inside the prior $\beta$ grains. It seems that nucleation of the $\alpha$ phase inside the prior $\beta$ grains was more heterogeneous in isothermal treatment than in continuous cooling. As shown in Figure $9 b$, the lamellae $\alpha$ were clustered inside the prior $\beta$ grains. There were a lot of $\beta$ blocks free of $\alpha$ precipitates. At long time holding, there were still some $\beta$ blocks without $\alpha$ precipitates (Figure 9c). In isothermal holding, the driving force for phase transformation is invariable. To overcome the energy barrier of nucleation, the existing $\alpha$ precipitates are more favorable nucleation sites. This phenomenon is more significant at a lower holding temperature, as shown in Figure 10. The specimen was isothermally held at $600{ }^{\circ} \mathrm{C}$ for $60 \mathrm{~min}$. There were a lot of $\beta$ blocks without $\alpha$ precipitates. The size of the $\beta$ blocks were much larger than the lamellae length. Thus, such PFZs can be eliminated solely by the nucleation of new $\alpha$ phase.
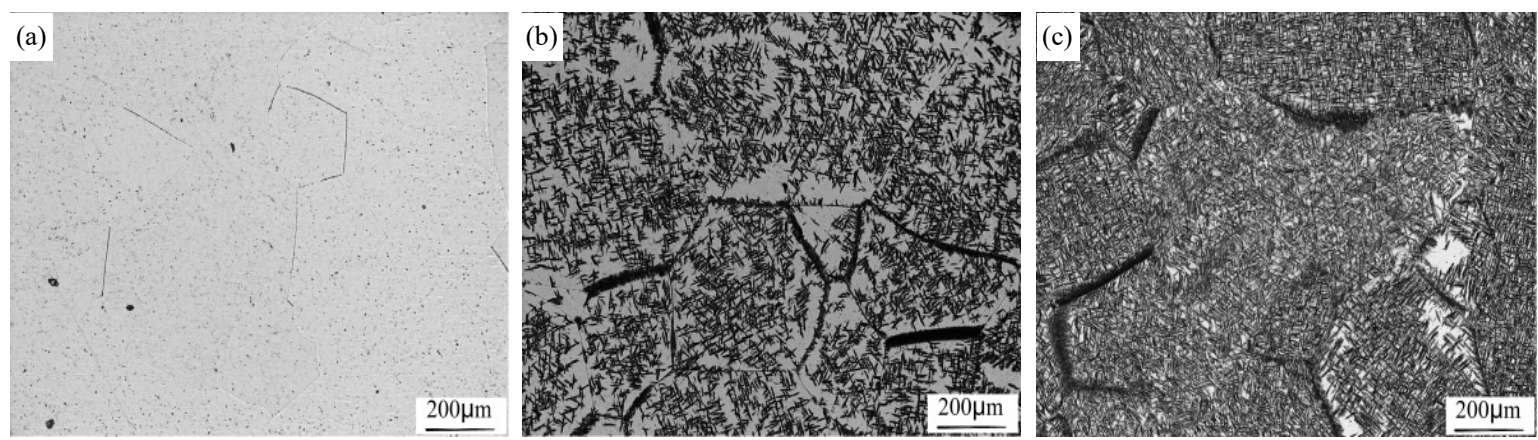

Figure 9. Microstructural developments during isothermal treatment at $700{ }^{\circ} \mathrm{C}$. The specimens were heated to $865^{\circ} \mathrm{C}$ and then held for (a) 10 , (b) 60, (c) $120 \mathrm{~min}$ at $700{ }^{\circ} \mathrm{C}$. 


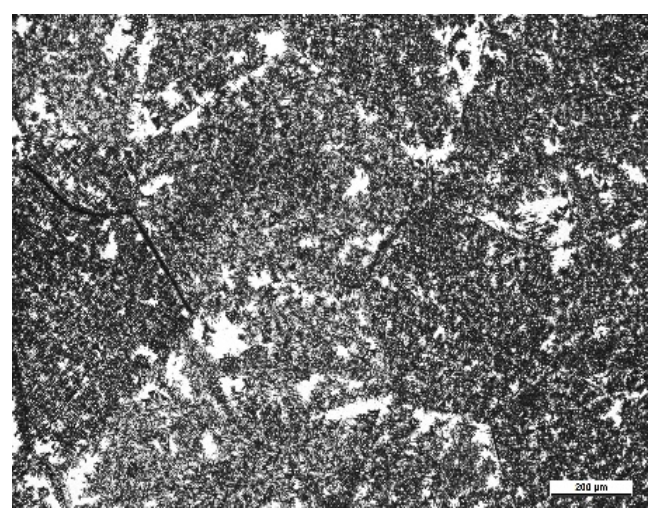

Figure 10. Microstructure of the specimen isothermally held at $600{ }^{\circ} \mathrm{C}$ for $60 \mathrm{~min}$ (solution temperature was $\left.865^{\circ} \mathrm{C}\right)$.

\section{Discussion}

When the near $\beta$ titanium alloy cools from the $\beta$ phase field, two kinds of $\alpha$ phase morphologies can be formed, which are frequently denoted as primary and secondary $\alpha$ phase, referring to their order of appearance during cooling $[9,13]$. The primary $\alpha$ phase forms predominantly at prior $\beta$ grain boundaries at relatively high temperatures. At lower temperatures, fairly thin plates nucleate both at grain boundaries and interior, which are denoted as secondary $\alpha$ plates [14]. The nucleation sites for $\alpha$ phase within the $\beta$ phase of $\beta$ titanium alloys include prior $\beta$ grain boundaries, $\beta / \omega$ interfaces, $\beta / \beta^{\prime}$ interfaces and other defects such as dislocations and intermetallic particles within the matrix [15].

The two-stage phase transformation was also observed in both the continuous cooling and the isothermal treatment in the current work. In the first stage, the $\alpha$ phase formed mainly at the grain boundaries. There were also some equiaxed $\alpha$ particles or thick $\alpha$ lamellae in the grain interior. The volume fraction of the $\alpha$ phase was very limited in this stage. In the second stage, the phase transformation proceeds rapidly by the nucleation and growth of thin lamellae $\alpha$. The critical temperature for the onset of the second stage decreases with the solution temperature and cooling rate in continuous cooling (Figure 7).

The nucleation sites in the first stage of continuous cooling were the same to that of isothermal treatment. However, the nucleation sites in the second stage varied with the heat treatment parameter. In the current work, the nucleation sites evolved in three different ways (Figure 11):

I-The lamellae $\alpha$ nucleated randomly at the grain boundaries and interior. This mode prevailed when the specimen was annealed at relatively low temperature and the cooling rate was relatively low at the first stage. This did not mean a homogeneous nucleation mode in the second stage. Due to the relative low cooling rate in the first stage, there would be plenty of intra-grain $\alpha$ particles serving as nucleation sites for the lamellae $\alpha$. Moreover, as the second stage began at a relative high temperature, the lamellae $\alpha$ could nucleate in other crystal defects other than the precipitated $\alpha$ phase formed in the first stage. This resulted in a homogeneous transformed structure.

II-Network nucleation inside the $\beta$ grain. This mode prevailed in furnace cooling of the specimen annealed at high temperature in which the cooling rate was relatively high at the first stage but low at the second stage. We monitored the Variation of temperature with time during furnace cooling. The temperature-time curve is shown in Figure 12. The cooling rate in furnace without specific control is about $9{ }^{\circ} \mathrm{C} / \mathrm{min}$ at $\mathrm{T}_{\beta}$ and about $0.5^{\circ} \mathrm{C} / \mathrm{min}$ at $600^{\circ} \mathrm{C}$. A network of lamellae $\alpha$ formed firstly in the prior $\beta$ grains, separating the $\beta$ grain into small cells. Then the $\alpha$ phase precipitated towards the cell interior and a relatively homogenous transformed structure was obtained.

III-Heterogeneous nucleation on the precipitated $\alpha$ phase. This mode prevailed in both furnace cooling and isothermal treatment. The high temperature annealing and rapid cooling in the first stage suppressed the precipitation of $\alpha$ phase in the first stage. Meanwhile, the second stage began at a 
relative low temperature, the lamellae $\alpha$ tended to nucleate heterogeneously at the existing $\alpha$ phase. Thus, the large size PFZs was prone to occurrence under such nucleation mode.

It is noteworthy that modes II and III took place in furnace cooling of specimen annealed at high temperature. The formation of network structure in the absence of substructure was rarely reported, to the best of the authors' knowledge. The energy barrier in phase transformation includes the strain energy due to volume change and the interfacial energy due to the formation of $\alpha-\beta$ interfaces. The spherical precipitates have the highest strain energy while the platelet precipitates have the lowest. The cell walls in the network structure can be taken as a set of flat surfaces, which are similar to the grain boundaries. Such a precipitation mode can minimize the overall strain energy.
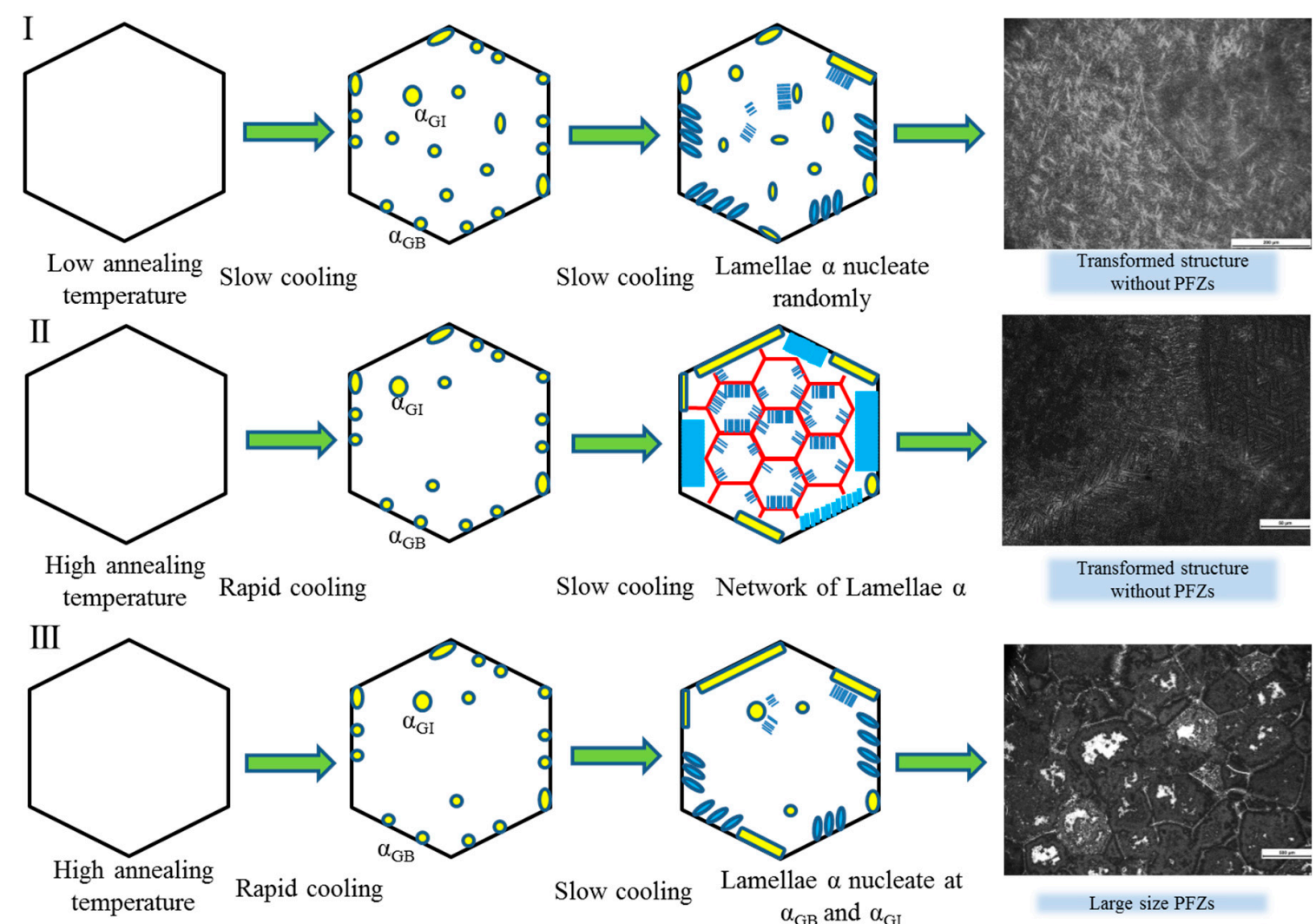

Solution in single $\beta$ phase field

1st stage of phase transformation

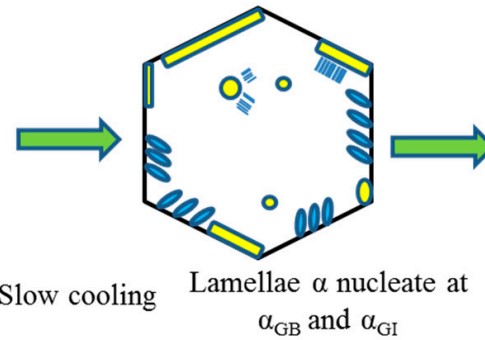

2nd stage of phase transformation

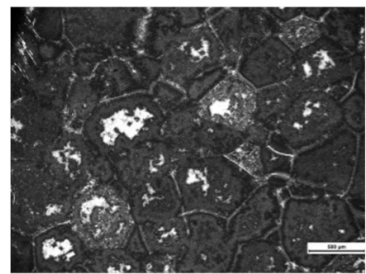

Large size PFZs

Microstructure

Figure 11. Schematic illustration of the nucleation modes in $\beta-\alpha$ phase transformation.

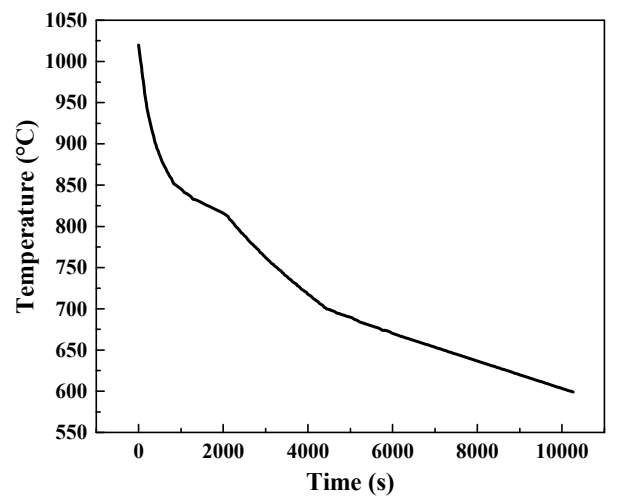

Figure 12. The variation of temperature with time during furnace cooling which is monitored by temperature thermocouple. 


\section{Conclusions}

This work investigated the formation mechanism of large size PFZs in the near- $\beta$ Ti-55531 titanium alloy by extensively experimental work. The following conclusions were drawn.

(1) Large size PFZs in the absence of micro segregation appeared only when the Ti-55531 titanium alloy was annealed at high temperature and furnace cooled. The formation of large size PFZs was not deterministic.

(2) A two-stage phase transition behavior was observed in slow cooling. The first stage involved the formation of grain boundary $\alpha$ and equiaxed $\alpha$ particles or thick $\alpha$ lamellae in the grain interior. The second stage referred to the nucleation and growth of lamellae $\alpha$. The critical temperature for the onset of the second stage decreased with increasing annealing temperature and cooling rate.

(3) The nucleation site evolves in three different modes during the second stage: I-random nucleation inside the $\beta$ grains, II-network nucleation inside the $\beta$ grains and, III-heterogeneous nucleation on the precipitated $\alpha$ phase. Both Mode II and Mode III were promoted at high annealing temperature, rapid cooling in the first stage and slow cooling in the second stage. Mode III resulted in the formation of large size PFZs while Mode II leads to a homogeneous transformed structure.

(4) Network of lamellae $\alpha$ (Mode II) formed in the absence of substructure. Such nucleation mode can minimize the strain energy in phase transformation. The competition between Mode II and Mode III resulted in the uncertainty of the microstructure.

Author Contributions: Investigation, X.J., X.S. and Q.L.; Resources, X.S. and X.F.; Writing—original draft, X.J.; Writing-review \& editing, X.F. and Q.L.

Funding: This research was funded by the National Natural Science Foundation of China (No. 51575449).

Conflicts of Interest: The authors declare no conflict of interest.

\section{References}

1. Meng, M.; Yang, H.; Fan, X.G.; Yan, S.L.; Zhao, A.M.; Zhu, S. On the modeling of diffusion-controlled growth of primary alpha in heat treatment of two-phase Ti-alloys. J. Alloys Compd. 2017, 691, 67-80. [CrossRef]

2. Boyer, R.R.; Briggs, R.D. The use of $\beta$ titanium alloys in the aerospace industry. J. Mater. Eng. Perform. 2005, 14, 681-685. [CrossRef]

3. Clément, N.; Lenain, A.; Jacques, P.J. Mechanical property optimization via microstructural control of new metastable beta titanium alloys. JOM 2007, 59, 50-53. [CrossRef]

4. Lenain, A.; Clément, N.; Jacques, P.J.; Véron, M. Characterization of the $\alpha$ phase nucleation in a two-phase metastable $\beta$ titanium alloy. J. Mater. Eng. Perform. 2005, 14, 722-727. [CrossRef]

5. Lütjering, G.; Albrecht, J.; Sauer, C.; Krull, T. The influence of soft, precipitate- free zones at grain boundaries in $\mathrm{Ti}$ and $\mathrm{Al}$ alloys on their fatigue and fracture behavior. Mater. Sci. Eng. A 2007, 468-470, 201-209. [CrossRef]

6. Liu, C.M.; Wang, H.M.; Tian, X.J.; Tang, H.B. Subtransus triplex heat treatment of laser melting deposited Ti-5Al-5Mo-5V-1Cr-1Fe near $\beta$ titanium alloy. Mater. Sci. Eng. A 2014, 604, 176-182. [CrossRef]

7. Narita, K.; Niinomi, M.; Nakai, M. Suyalatu Effect of heterogeneous precipitation caused by segregation of substitutional and interstitial elements on mechanical properties of a $\beta$-type Ti alloy. Mater. Sci. Eng. A 2015, 643, 109-118. [CrossRef]

8. Ogura, T.; Hirose, A.; Sato, T. Effect of PFZ and Grain Boundary Precipitate On Mechanical Properties and Fracture Morphologies in Al-Zn-Mg(Ag) Alloys. Mater. Sci. Forum 2010, 638-642, 297-302. [CrossRef]

9. Teixeira, J.D.; Héricher, L.; Appolaire, B. Prediction of the kinetics of the phase transformations and the associated microstructure during continuous cooling in the Ti17. J. Phys. 2004, 120, 93-101.

10. Li, T.; Kent, D.; Sha, G.; Cairney, J.M.; Dargusch, M.S. The role of $\omega$ in the precipitation of $\alpha$ in near- $\beta$ Ti alloys. Scr. Mater. 2016, 117, 92-95. [CrossRef]

11. Gornakova, A.S.; Straumal, B.B.; Nekrasov, A.N.; Kilmametov, A.; Afonikova, N.S. Grain Boundary Wetting by a Second Solid Phase in Ti-Fe Alloys. J. Mater. Eng. Perform. 2018, 27, 4989-4992. [CrossRef] 
12. Straumal, B.B.; Kilmametov, A.R.; Ivanisenko, Y.; Gornakova, A.S.; Mazilkin, A.A.; Kriegel, M.J.; Fabrichnaya, O.B.; Baretzky, B.; HahnPhase, H. Transformations in Ti-Fe Alloys Induced by High-Pressure Torsion. Adv. Eng. Mater. 2015, 17, 1835-1841. [CrossRef]

13. Leyens, C.; Peters, M. Titanium and Titanium Alloys: Fundamentals and Applications; Wiley-VCH: Weinheim, Germany, 2005; p. 401.

14. Bohemen, S.M.C.V.; Kamp, A.; Petrov, R.H.; Kestens, L.A.I.; Sietsma, J. Nucleation and variant selection of secondary $\alpha$ plates in a $\beta$ Ti alloy. Acta Mater. 2008, 56, 5907-5914. [CrossRef]

15. Duerig, T.W.; Williams, J.C. Beta Titanium Alloys in the 80s: Proceedings of the Symposium; Metallurgical Society of AIME: New York, NY, USA, 1984; pp. 19-67.

(C) 2019 by the authors. Licensee MDPI, Basel, Switzerland. This article is an open access article distributed under the terms and conditions of the Creative Commons Attribution (CC BY) license (http://creativecommons.org/licenses/by/4.0/). 